\title{
THE EFFECTS OF TEACHER INTERVENTION \\ AND PEER INTERACTION ON FIFTH GRADE STUDENTS' \\ STUDIO ART PERFORMANCE
}

\section{Karen Kakas}

\section{Introduction}

At a time when proponents of discipline-based art education are decreasing the role of studio performance in the art curriculum, it has become imperative that art educators determine the contribution of studio activities to art learning. Yet they continue to debate the form teacher intervention should take to enhance learning in these experiences. Long looked upon as too individualized and mysterious to permit objective study, art production must be thoroughly examined to determine how (in what ways and to what degree) teacher intervention affects performance and subsequent learning. The major purpose of this study-in-progress is to examine how varying forms of teacher intervention during the art-making process affect 5 th grade students' studio art performance as manifested in observation and fantasy drawings.

Traditionally, the teacher has been viewed as the sole stimulus of learning in the classroom. While a number of general education researchers have examined the role of peer interaction in learning, few art educators are exploring this area. A second purpose of this study is to investigate the nature of peer interaction and its effect on studio performance.

Due to the lack of substantive reporting in art education on the art teaching/learning process during studio activities, this study will add to the knowledge base that other art educators can use as they reflect on their oven teaching behaviors. Investigation of peer interaction will also contribute to the understanding of art-making processes as they occur in the classroom.

For many years the art education profession maintained a child-centered approach in teaching art to young people. Teachers were to respond to children's needs and not impose images or standards of any sort on them. By the 1960's, a number of art educators were critical of this attitude, believing that such methods contributed little to youngsters' art knowledge. By the 1970 's major art education textbooks recommended that teachers provide guidance, especially by using skillful questioning strategies, which were considered the most effective way to nurture studio performance. They cautioned against overdirective teaching, especially in the studio component of the curriculum, claiming that such behavior would hinder children's individual, creative expression. The prevailing view held that concrete teacher feedback or suggestions correlated with imposition of adult standards or expectations on children's studio performance.

However, many of the field's assumptions about what and how to teach art are supported by little systematic study of the art teaching-learning process. A number of studies in the 1960's investigated the effects of teacher feedback on college student art production, and the value of recent studies 
focusing on elementary age children is limited by inadequate research designs and methods which often yield questionable or inconclusive findings. Research on particular instructional issues has failed to produce the collective evidence that explains the effect of teacher intervention in studio art learning experiences. Such practices contribute to what Packard (1984) contends is a lack of research on effective teaching in art education. Chapman (1982) voices a similar concern:

The scarcity of research on teachers and the teaching of art may be due, in part, to the active and visible role we give to the child as creator, and the supportive background role we seem to prefer for the art teacher. Our research offers little insight into the character of interactions in the classroom, or what students learn. (p. 107)

Several art educators have recently focused on questioning strategies and teacher/student dialogues in the classroom. Hamblen (1985) has primarily studied the use of questions in critical/historical group discussions for which she has developed a "cognitive-level/content-area model" for question construction. Taunton (1985) has begun to report on her descriptive studies of dialogues between art teachers and preschool children. But this researcher is not aware of art education research which compares the effects of questioning strategies to other teaching methods.

A portion of peer interaction research has studied the nature of spontaneous verbal communication among students that results in peer teaching (Cooper,Marquis, \& Ayers-Lopez, 1982). Their work complements others who are concerned with the positive effects of peer interaction on student achievement and productivity (Johnson, 1981). Several art educators have reported on peer interaction (Alexander, 1984; Swann, 1985). Both have focused on very young children as they described the nature of conversations during studio art sessions, but they have not investigated the effects of these interactions on art learning or how peer interaction may be influenced by the form of teacher feedback.

\section{Method}

\section{Design}

The subjects consisted of fifty-four 5 th grade students who were randomly selected from three elementary schools in a midwestern metropolitan school district.

Three levels of teacher intervention and three levels of task order formed between-subject groups; six levels of drawing task comprised a within-subjects variable. Eighteen subjects were randomly assigned to each teacher inventior: method and were further divided into three small groups, each receiving one of the three task orders. Therefore, the researcher administered the six drawing tasks to nine groups, each containing six subjects.

At a pretest orientation session subjects were introduced to video and 
audio equipment, completed an art interest questionnaire, and created a drawing which was to include a minimum of three animals. They then attended six 60-minute drawing task sessions, two focusing on observational drawing, two focusing on fantasy drawing, and two that combined observation with fantasy drawing. The drawing sessions, which had a Creatures in Art theme, included the following tasks: (a) The Great Horned Owl,

(b) Fantasy Flying Creatures, (c) Outerspace Toys, (d) Outerspace Creatures, (e) Underwater World of Sea Creatures, and ( $f$ ) The Peaceable Kingdom. All drawings were completed on $12 \times 18$ inch drawing paper with an assortment of colored markers.

All groups were given the same introduction to a drawing task, but each group received one of three forms of teacher intervention during the art-making phase of the lesson: nonspecific feedback, open-ended questioning feedback, or directive feedback.

In nonspecific feedback groups the researcher emphasized that students were to make their own decisions about their work. They were reminded that the drawings must be their own creations and if advice is given, their drawings would reflect the researcher's ideas. From time to time both nonspecific and concrete praise was given to each subject or to the group. The researcher was not to provide any guidance or suggestions, except to occasionally remind the entire group of lesson objectives. Nonspecific praise statements included, "You're working very hard today," or, "You're doing a good job." Concrete praise statements referred to one of the lesson objectives as the researcher reacted to a particular aspect of a subject's drawing. An example of this form was, "Your owl fills the page very well," or, "I like the color plan on the legs of your creature." Periodically the researcher circulated among the group to provide supportive comments, e.g., "This takes a lot of practice, so don't worry if there is some distortion in your drawing of the owl." Much of the time the researcher sat nearby and recorded field notes about the session.

In the open-ended questioning feedback groups the researcher asked many questions related to objectives discussed at the beginning of the session. This strategy was meant to encourage students to reflect about various aspects of their drawings. Concrete questions, while referring to specific qualities seen or absent in the drawings, allowed for open-ended reflection. The researcher initiated such dialogues as well as responded in this manner when asked for assistance by subjects. Examples of such questions were: "How will you decorate the wings of your creature?" "Is the V-shape on the owl's face as obvious in your drawing as it is on the owl? If not, how could you make it more obvious?" "What type of patterns will you put on the legs of your flying creature?" When asked for an opinion about a particular drawing, the researcher responded with a positive comment about a specific characteristic of the work which related to one of the discussed objectives of the task. The researcher frequently moved among the subjects while they drew and occasionally sat nearby to write notes about the session. Any praise offered by the researcher addressed specific qualities in drawings and related to objectives delineated for the task.

Subjects in the third teacher intervention groups received concrete, directive feedback while performing the drawing tasks. The researcher's view-

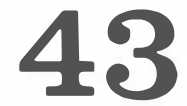


point was more obvious than in the more subtle questioning strategies of the second method. Such statements included: "Compare your drawing of the overall shape of the owl with the owl as you see it. See how much wider the owl is. You need to fill him out a bit more. Just draw a new line for the edge of the wing and your first line could become part of the pattern part of the wing." "The chest part of the owl's body is still rather empty. You've thought of good ways to put patterns on the head and wings. It's not important to fill up the entire owl, but in the time you have left, show part of the pattern in the chest area. And be sure to look at the owl to compare the patterned sections. How are they different?" When a subject asked for assistance, the researcher offered one or more suggestions for consideration or demonstrated an aspect that was particularly troublesome to the subject. The latter occurred primarily in the observation tasks. The researcher systematically moved throughout the group to respond to questions or provide comments, concrete praise, or suggestions. Questioning strategies were also used, but less frequently than in the open-ended questioning feedback groups.

Post-treatment interviews will be conducted individually with each subject. At this time subjects will complete self-evaluation check lists for each drawing task. Subjects will also point out their most and least favorite drawing tasks and explain their selections. They will rate themselves as artists and describe their attitudes about participating in the study. And finally, the researcher will show finished and unfinished drawings by other children and ask the subject to evaluate and/or offer suggestions to the maker. The researcher will also interview subjects' classroom teachers to gain additional contextual information. Both series of interviews will be audiotaped.

\section{Data analysis}

Criterion-referenced evaluation will be used to assess student ar $\mathbf{t}$ products on the basis of performance objectives established for each drawing task. Three art education doctoral students will be trained to score the experimental drawings. The judges will be provided with printed lists of objective statements for each task each criterion accompanied by photographs of two sample drawings, one exemplifying a low rating and the other exhibiting a high rating, which are scored 1 (low) to 5 (high). Inter-rater reliability will be assessed by requiring the judges to rescore a group of randomly selected drawings they had previously appraised. To complement the external evaluation, during a posttest interview with the researcher, each subject will complete self-evaluation check lists containing criterion statements identical to those used by the judges.

Peer interaction will be studied naturalistically through the use of audio and videotapes. This documentation will also inform the researcher if she used each teacher intervention method consistently throughout the groups and whether the instructional motivation presentations at the beginning of each task session were alike for all groups. Analysis of variance methods will be used to analyze the drawing score data, and to determine whether significance differences occur red between subjects' self-evaluation scores and the juciges' ratings.

Analysis of peer interaction will occur through review of audio and videotapes which document all interaction in each task session. A typology of those interactions will be developed, i.e., a categorical system of patterns of verbal and nonverbal behaviors will be coded for each group. Subject/researcher interactions will

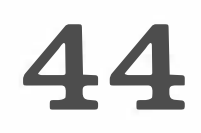


also be coded. Comparison of the patterns of behavior will be made in relation to the three teaching feedback methods. For example, will certain patterns of interaction occur more often during one feedback strategy than another?

The use of Pre-Treatment Student Art Attitude/Information Questionnaire and post-treatment interviews with subjects and with their classroom teachers will provide contextual data about the subjects which will contribute to the analysis of the experimental data results. The descriptive component of the study will enhance the experimental findings by placing the latter within a contextual frame work. Results of the experimental and descriptive data analysis will be provided at a later date.

\section{REFERENCES}

Alexander, R. (1984). First graders' classroom conversations about artmaking: Social life, fantasy, play, verisimiltude, and procedures. In Koroscik, J. S. E Barrett, T. (Eds.). Proceedings Journal: Arts $\&$ Learning SIG, 2, American Educational Research Association.

Chapman, H. (1982). Instant art, instant culture: The unspoken policy for American schools. New York: Teachers College Press.

Cooper, C. R., Marquis, A., \& Ayers-Lopez, S. (1982). Peer learning in the classroom: Tracing developmental patterns and consequences of children's spontaneous interactions. In L. C. Wilkinson (Ed.), Communicating in the classroom (pp. 69-83). New York: Academic Press.

Hamblen, K. (1985, April). Constructing questions for discipline-based art instruction within a content-area/cognitive-level model. Paper presented at the meeting of the National Art Education Association, Dallas, Texas.

Johnson, D. W. (1981). Student-student interaction: The neglected variable in education. Educational Researcher, 10 (1), 5-10.

Packard, S. (1984). Higher education division news: True confessions. NAEA News, $26(1), 11$.

Swann, A. (1985, April). Patterns of peer influence in art. Paper presented at the meeting of the national Art Education Association, Dallas, Texas.

Taunton, M. (1985, April). Classroom interaction during art activities: Opportunity for the development of critical awareness. Paper presented at the meeting of the National Art Education Association, Dallas, Texas. 